\title{
Diagnostic Accuracy of 3d Scan and Plain Radiograph in Diagnosis of Midface Fractures
}

\author{
Farhat Abbas Saima Munir Sohail Fareed Noorul Ain Arshad Khalil Ahmad Khan \\ Qamar uz Zaman \\ Department of Oral \& Maxillofacial Surgery, Nishtar Institute of Dentistry, Multan
}

\begin{abstract}
OBJECTIVE: To determine the diagnostic accuracy of plain radiographs and 3D scan in diagnosis of mid face fractures by taking surgery findings as a gold standard. STUDY DESIGN: Cross Sectional Study SETTING: study was carried out at Department of Oral \& Maxillofacial Surgery, Nishtar Institute of Dentistry, Multan. DURATION: Study was completed in 6 months from May, 2017 to November 2017in Nishtar . Methodology: 181 Patients were included from Department of Oral \& Maxillofacial Surgery, Nishtar Institute of Dentistry, Multan after taking informed consent and permission from ethical committee and research department. Demographic information of patients (name, age, gender, duration of Fracture had taken. Patients from both gender with age range of 18-35 years having Maxillofacial trauma $<10$ days were included in this study and patients in which CT scan was contraindicated and those taken any surgical treatment for facial trauma were excluded in this study. Radiographic examination for the cranio-facial complex had performed for all patients followed by routinely and according to the needs of each individual case. RESULTS: From 181 patients, the minimum age was 18 years and maximum age was 35 years. According to plain radiographs, fracture was detected in $88.4 \%$ patients. By using 3D scan, fracture was detected in $96.7 \%$ patients. Sensitivity of 3D scan for detection of fracture was calculated as $98.13 \%$, specificity was $14.28 \%$, positive predicted value was $89.71 \%$, negative predicted value was 50\% and diagnostic accuracy was $88.39 \%$. CONCLUSION: Among 181 patients, fracture was detected in $88.4 \%$ patients by using plain radiographs. By using 3D scan, fracture was detected in $96.7 \%$ patients. Sensitivity of 3D scan for detection of fracture was calculated as $98.13 \%$, specificity was $14.28 \%$, positive predicted value was $89.71 \%$, and diagnostic accuracy was $88.39 \%$.
\end{abstract}

Keywords: 3D scan, plain radiographs, mid face fractures

DOI: $10.7176 / \mathrm{JMPB} / 60-01$

Publication date:October $31^{\text {st }} 2019$

\section{INTRODUCTION}

Most commonly mid face fractures occur because of motor vehicle accidents, falls, assaults and blunt traumas. $(1,2)$ Computed tomography $(\mathrm{CT})$ is now a standard imaging technique for the evaluation of injuries to determine which patients require surgical intervention. $(3,4)$

For the planning of the restoration of facial skeleton, surgeon's need thorough understanding of degree and nature of facial skeleton damage. .Minor, even clinically irrelevant fractures of the facial skeleton can be visualized by CT scan.(5) For the patients with blunt facial trauma to detect both soft tissue and osseous defects including even hairline which often get diagnosed in routine examination, high resolution computed tomography with 3D reconstruction has been increasingly in practice.(6) In past, conventional Palin film radiographs were mostly used for the evaluation of facial injuries. Different radiographs can be used according toh the suspected type of injury. These may include lateral, Caldwell projections and occipitomental view. (7) Conventional radiographs are sensitive to cranial vault fractures not to fractures of skull base and facial skeleton. $(8,9)$

Conventional X-ray is no longer the standard in radiological imaging for cranio-facial trauma detection. CT is widely available and allows fast scanning of the patient.(10) CT scan enables a precise diagnosis of all kind of fractures of the facial skeleton and skull base, and it also provides essential information about intracranial bleeding and injuries to the cerebrum. $(8,9) \mathrm{CT}$ scan can help in better understanding some of the more complex facial fractures and can also aid in planning surgery when reconstruction is necessary.(7)

The rationale of this study is to determine the diagnostic accuracy of plain radiographs and CT scan in diagnosis of mid face fractures so that precise treatment can be done.

\section{METHODOLOGY}

Total 181 Patients were included from Department of Oral \& Maxillofacial Surgery, Nishtar Institute of Dentistry, Multan after taking informed consent and permission from ethical committee and research department. Demographic information of patients (name, age, gender, duration of Fracture had taken. Patients from both gender with age range of 18-35 years having Maxillofacial trauma $<10$ days were included in this study and patients in which CT scan was contraindicated and those taken any surgical treatment for facial trauma were excluded in this study. Radiographic examination for the cranio-facial complex had performed for all patients followed by routinely and according to the needs of each individual case. The extra-oral projections included 
submento-vertex, reverse Town's, Postero-anterior, Water's view, Orthopantamogram, panoramic, transpharyngeal, lateral oblique and true lateral views had followed by non-contrast CT scan of the face. The CT examination had performed on the Siemens Somatom Balance (spiral rotating system) at settings of $130 \mathrm{kVp}, 90$ $\mathrm{mA}$ and scan time of 20s. 3D facial reconstruction CT unit had used and the slice thickness had used in this study ranges from $2 \mathrm{~mm}$ to $6 \mathrm{~mm}$. continuous volume scan had taken in axial, coronal and saggital plane, which makes an image of three dimension or a 3D reconstruction.

All patients had then sent for surgical treatment. Data had collected regarding diagnosis of mid face fractures by plain radiographs and CT scan. Data had recorded on especially designed proforma.Data analysis had performed by using SPSS-23 software. Data for age and duration of fracture had described by using Mean \pm SD and for age groups and gender by frequency and percentages. Sensitivity, specificity, Positive predicted value, Negative predictive value and diagnostic accuracy for plain radiographs and 3D scan against surgery findings had calculated by using 2 X2 table. Effect modifiers like age, gender and duration of fracture had controlled by stratification. Post stratification sensitivity, specificity, positive predicted value, negative predictive value and diagnostic accuracy had calculated.

\section{RESULTS}

From 182 patients, it was observed that the minimum age was 18 years and maximum age was 35 years with mean \pm standard deviation as $26.43 \pm 4.66$ years. The minimum duration of fracture was 1 day and maximum was 9 days with mean \pm standard deviation as $3.15 \pm 2.61$ days (Table 1). There were $108(59.7 \%)$ male patients and 73 $(40.3 \%)$ female patients (Table 2$)$. According to plain radiographs, fracture was detected in $160(88.4 \%)$ patients while it was not detected in $21(11.6 \%$ ) patients (Table 3). By using 3D CT scan, fracture was detected in 175 (96.7\%) patients while it was not detected in $6(3.3 \%)$ patients (Table 4). Sensitivity of 3D scan for detection of fracture was calculated as $98.13 \%$, specificity was $14.28 \%$, POSITIVE predicted value was $89.71 \%$, negative predicted value was $50 \%$ and diagnostic accuracy was $88.39 \%$. By stratification of age, the diagnostic accuracy of $<26$ years age group was $93.68 \%$ and the diagnostic accuracy of $\geq 26$ years age group was $83.72 \%$. The diagnostic accuracy was found as $87.96 \%$ in males while in females it was $89.04 \%$. By stratification of age, the diagnostic accuracy of $<5$ days was $88.55 \%$ and the diagnostic accuracy of $\geq 5$ days was $86.0 \%$.

\section{Table: 1 Descriptive Statistics $n=181$}

\begin{tabular}{|l|l|l|l|l|}
\hline & Minimum & Maximum & Mean & Std. Deviation \\
\hline Age (years) & 18 & 35 & 26.43 & 4.66 \\
\hline Duration of fracture(days) & 1 & 9 & 3.15 & 2.61 \\
\hline
\end{tabular}

Table2: Distribution of $\operatorname{Gender}(n=181)$

\begin{tabular}{|l|l|l|}
\hline Gender & Frequency & Percentage \\
\hline Male & 108 & $59.7 \%$ \\
\hline Female & 73 & $40.3 \%$ \\
\hline Total & 181 & $100 \%$ \\
\hline
\end{tabular}

Table 3. Distribution of plain radiographs $\operatorname{accuracy}(n=181)$

\begin{tabular}{|l|l|l|}
\hline Plain radiographs accuracy & Frequency & Percentage \\
\hline Positive & 160 & $88.4 \%$ \\
\hline Negative & 21 & $11.6 \%$ \\
\hline Total & $\mathbf{1 8 1}$ & $\mathbf{1 0 0}$ \\
\hline
\end{tabular}


Table 4. Distribution of 3D scan accuracy $(n=181)$

\begin{tabular}{|l|l|l|}
\hline 3D scan & Frequency & Percentage \\
\hline Positive & 175 & $96.7 \%$ \\
\hline Negative & 6 & $3.3 \%$ \\
\hline Total & $\mathbf{1 8 1}$ & $\mathbf{1 0 0}$ \\
\hline
\end{tabular}

\section{DISCUSSION}

In previous studies,3D-CT reconstructed images enabled the radiologist to improve the visualization and to manipulate volumetric data readily, to establish an accurate application to maxillofacial region.[11,12) 3D-CT scan reproduces the osseous structures, providing complete inspection of the reproduced structure from any viewpoint (including internal inspection), better understanding of anatomy. It also aids the evaluation of the operative results for craniofacial surgery. (13) Rhea, et al.[14] (1999) and Carls, et al.[15] (1994) also observed that 3D images provided an easy detection of specific characteristics of facial asymmetries, midface defects and skull vault defects and alsofractures which are associated with extensive bone displacement are better localized by using 3D imaging technique.

Ohkawa, et al.[16] (1997) reported that both 2D-CT and 3D CT techniques presented a similar sensitivity for the diagnosis of fractures in the mandibular region, though 3D-CT imaging allowed a better visualization of the fractured site.In another study, it was found [17] that the facial radiograph for detection of fracture has the sensitivity of $90 \%$, the specificity of $94.7 \%$, and the accuracy of $91 \%$ (17).But in our study accuracy was $88 \%$. Although facial radiography was associated with a high diagnostic rate,but its ability to visualize the complex facial fractures such as fractures at the nasal bone, maxillary sinus, mandible bones and the orbital rim is still limited.[18-20] However many studies show that the result of facial CT scan is superior to that of facial radiographs for the accurate diagnosis of the facial skeleton.[21].

\section{CONCLUSION:}

Among 181 patients, fracture was detected in $88.4 \%$ patients by using plain radiographs and by using 3D scan, fracture was detected in $96.7 \%$ Sensitivity of 3D scan for detection of fracture was calculated as $98.13 \%$ and diagnostic accuracy was $88.39 \%$. The results showed 3D scan is superior to the conventional facial radiographs.

\section{REFERENCES:}

1.IidaS., Kogo M, Sugiura T, Mima T, Matsuya T. Retrospective analysis of 1502 patients with facial fractures. Int J Oral Maxillofac Surg 2001; 30(4): 286-290

2. GassnerR, Tuli T, Hachl O, Rudisch A, Ulmer H. Cranio-maxillofacial trauma: a 10 year review of 9,543 cases with 21,067 injuries. J Craniomaxillofac Surg 2003; 31(1): 51-61.

3. CooperPW, Kassel EE, Gruss JS. High-resolution CT scanning of facial trauma. AJNR Am J Neuroradiol 1983; 4(3): 495-498.

4. LaineFJ, Conway WF, Laskin DM. Radiology of maxillofacial trauma. Curr Probl Diagn Radiol 1993; 22(4): $145-188$.

5. Daffner RH. Imaging of facial trauma. Semin Musculoskelet Radio 1998; 2(1): 65-82

6. Agarwala A, Kumarb N, Sharmab N. 2D and 3D CT scan a diagnostic adjunct or necessity in maxillofacial trauma. Indian J Dent. 2012;1-5.

7. Kassel EE. Traumatic injuries of the paranasal sinuses. Otolaoyngol Clin North Am 1988;21:455-93.

8. Hassfeld S, Muhling J, Zoller J (1998). Possibilities and developments of intraoperative image-guided surgery in craniofacial surgery. Mund Kiefer Gesichtschir $2: 20-24$.

9. Gellrich NC, Schramm A, Schmelzeisen R (2003) . Clinical application of computer-assisted reconstruction in complex posttraumatic deformities. In: P Ward-Booth, BL Eppley, R Schmelzeisen (eds), Maxillofacial trauma and esthetic facial reconstruction . Churchill Livingstone : Edinburgh , pp 215 - 228.

10. Yokata H, Kurowa A, Otsuka T (1991). Significance of MRI in acute head injury . J Trauma $1: 351-357$.

11.Cavalcanti MGP, Haller JW, Vannier MW. Three-dimensional computed tomography landmark measurement in craniofacialsurgical planning: experimental validation in vitro. J Oral Maxillofac Surg. 1999;57(6):690-4.

12. Buitrago-Tellez CH, Schilli W, Bohnert M, Alt K, Kimmig M. A comprehensive classification of craniofacial fractures: postmortem and clinical studies with two- and three-dimensional computed tomography. Injury 2002;33(8):651-68.

13.Mayer JS, Wainwright DJ, Yeakley JW, Lee KF, Harris JH Jr, Kulkarni M. The role of three-dimensional computed tomography in the management of maxillofacial trauma. J Trauma. 1988;28(7):1043-53. 
14.Rhea JT, Rao PM, Novelline RA. Helical CT and three-dimensional CT of facial and orbital injury. Radiol Clin North Am.1999;37(3):489- 513.

15.Carls FR, Schuknecht B, Sailer HF. Value of three-dimensional computed tomography in craniomaxillofacial surgery. J Craniofac Surg. 1994;5(5):282-8.

16. Ohkawa M, Tanabe M, Toyama Y, Kimura N, Uematsu K, Satoh G. The role of three-dimensional computed tomography in the management of maxillofacial bone fractures. Acta Med Okayama.1997;51(4):219-25.

17. Chiu P, Chen J, Ko P, Chang C. Clinical Assessment of the Diagnostic Value of Facial Radiography in Facial Trauma Patients at the Emergency Department. Chinese J of Radiology-Taipei-. 2005 Dec 1;30(6):327.

18.Kassel EE. Traumatic Injuries of the Paranasal Sinus. Otolaryngol Clin North Am 1988; 21: 455-493.

19. Noyek AM, Kassel EE, Wortzman G, Jazraey H, Greyson ND, Zizmor J. Contemporary radiologic evaluation in maxillofacial trauma: Symposium on trauma to the head and neck. Otolaryngol Clin North Am 1983 ;16: 473-508.

20.. DelBalso AM, Hall RE. Advances in maxillofacial imaging. Curr Probl Diagn Radiol 1993; 22: 91-142.

21. Tanrikulu R. Erol B. Comparison of computed tomography with conventional radiography for midfacial fractures. Dento Maxillo Fac Rad 2001; 30: 141- 146. 